\title{
E1 factor energético (hidrocarburos) en las relaciones internacionales de América Latina
}

\section{INTRODUGCIÓN}

Hasta los primeros años de la década del setenta, los estudios sobre el papel de los recursos energéticos en América Latina tendieron a concentrarse en los aspectos técnicos y económicos. Existió relativamente poco interés en analizar, de manera integral, el papel de estos recursos en la ecuación de la política exterior e internacional de América Latina, salvo en el caso de aquellos países para los cuales los hidrocarburos, y fundamentalmente, el petróleo, constituían su principal producto de exportación (ej.: México, Bolivia, Venezuela). Los estudios de casos nacionales que se realizaron con un enfoque político, generalmente bajo el enfoque de la dependencia o de las teorías marxistas, centraron su atención en los conflictos que se suscitaban con las principales empresas transnacionales petroleras y las grandes potencias occidentales.

El impacto sobre el sistema económico y político-estratégico internacional que tuviera lugar como consecuencia de la acción de la OPEP a partir de 1973; el proceso de revalorización de ciertos recursos minerales y energéticos en virtud de las necesidades estratégicas de los Estados Unidos y de los restantes países industrializados $y$, la importancia creciente que adquirió para algunos de los paises de la región el acceso a un desarrollo energético nuclear progresivamente autónomo (ej.: Argentina, Brasil), contribuye a ampliar y profundizar el tratamiento de los factores energéticos como un componente de sumo peso en la ecuación de la política externa e internacional contemporánea ${ }^{1}$. El rápido resurgimiento de los temas de política económica como centro de gravedad de los conflictos que debe enfrentar la política internacional de los países en

${ }^{1}$ Sobre las posibilidades de desarrollo energético ver, entre otros, Jorge Sábato Recursos Energéticos y Dependencia Tecnológica, Seminario Internacional "Energía y Desarrollo", OLADE-FLACSO-ILdrs (Quito, 15-18 julio 1980); Miguel S. Ussher, "El papel de América Latina en el problema energético mundial", Segunda Conferencia Internacional sobre América Latina y la Economia Mundial (Buenos Aires, Instituto Torcuato Di Tella - OEA, $26-29$ agosto, 1980). 
Carlos J. Moneta / E1 factor energético (hidrocarburos) en las relaciones...

desarrollo (comercio; inversiones; control y uso de los recursos naturales, deuda externa), favorece que los problemas energéticos sean considerados mediante enfoques capaces de tener debidamente en cuenta las interrelaciones existentes entre los factores políticos y económicos.

Entre los hidrocarburos, el petróleo ocupa una posición clave en el balance energético global. Al corresponderle cerca del 65-70\% del consumo energético mundial y dada la asimétrica localización de las reservas hasta ahora conocidas $60 \%$ de ellas se encuentran ubicadas en Medio Oriente) ${ }^{2}$, este recurso adquiere enorme releyancia económica, política y estratégica. Entre otros elementos, la posesión o carencia de petróleo, su precio y las condiciones de estabilidad o inestabilidad de su suministro afectarán de manera crítica las posibilidades de desarrollo de la mayor parte de los países durante las décadas de 1980 y 1990, contribuyendo a modificar la distribución de los factores de poder en los planos mundial y regional.

América Latina presenta una enorme contradicción con respecto a la utilización de su petróleo. Pese a ser una región con capacidad de autoabastecerse, a fines de la década del setenta exportaba el $77 \%$ de este hidrocarburo e importaba el equivalente a un $91 \%$ de sus necesidades de consumo de fuentes externas ${ }^{3}$.

Hasta el presente y pese a los avances realizados en el control y utilización de los hidrocarburos y en el desarrollo de otras fuentes de energía por estados nacionales en forma individual $y$, posteriormente, por la Organización Latinoamericana de Energía (OLADE), áreas vitales (tecnología, inversiones, etc.) de la exploración y producción, la distribución y el estilo de consumo de energía responden, en grado significativo, a pautas inherentes al modelo de "economía de mercado". Éstas permiten a operadores internos (actores subnacionales) y externos (actores transnacionales y nacionales) ejercer un grado considerable de influencia política y económica ${ }^{4}$. El proceso seguido para el manejo de los recursos energéticos en Colombia, hasta hace pocos años, da una buena idea de ello. La orientación otorgada hasta fines de la década del setenta a Ia acción de PETROBRas en Brasil ofrece un ejemplo distinto, de signo equivalente, esta vez con una empresa estatal. El desmantelamiento de

2Datos calculados según cifras proporcionadas por el Guadro a del documento: Las Relaciones Económicas Externas de América Latina en los años ochenta, E/GEPAL/G. 1160 (Saritiago, Chile, CEPAL).

${ }^{3} \mathrm{EI}$ documento de la CEPAL, El desarrollo de América Latina en los años ochenta, E/CEPAI/G. II50; E/CEPAL/GEGAN 5/6. 3 (Santiago, GEPAL, 4. 2. 1981).

'Sobre el tema de la supuesta separación efectiva entre el sistema político $y$ el sistema económico en los regímenes de economía libre de mercado, ver Charles E. Lindblom, Politics and Markets. The World's Political-Economic Systems (New York, Basic Books, 1977). El Dr, Lindblom demuestra el alto grado de control que ejerce el régimen de economa de mercado sobre el sistema polf́tico. 
Yacimientos Petrolfferos Fiscales (YPF), de Argentina realizado durante el gobierno militar del período 1976-1983, constituye otro ejemplo de lo afirmado 5 .

En consecuencia, el rumbo que adopte en el futuro el desarrollo de Ia energía en América Latina dependerá, en medida considerable, de que exista una voluntad política y una acción coordinada a largo plazo por parte de los países de la región, en favor de un desarrollo de carácter autonómico y solidario o de que prevalezcan la dispersión de los esfuerzos y una visión limitada e inmediata en la definición de los intereses nacionales.

Dados los diversos factores señalados, este trabajo se propone comentar algunos aspectos de la incidencia del factor energético en las políticas externas de los países de la región vinculadas a la situación que ésta enfrenta en el contexto internacional. Asimismo, se tendrán en cuenta, mediante la observación de algunos casos, los factores de cooperación y de conflicto que surgen en las relaciones intrarregionales y extrarregionales. Estos factores afectan la viabilidad de la estrategia diseñada en el seno de la OLADE para dar soluciones a los problemas de la región en el campo energético y para incrementar su poder de negociación ante los actores externos.

El carácter predominante que posee el petróleo en los problemas energéticos mundiales y regionales contemporáneos conduce a que este trabajo, dadas sus limitaciones, concentre el análisis en este recurso, en el marco de los hidrocarburos. Los restantes componentes serán tenidos en cuenta en la medida que resulta indispensable. No obstante, ello no implica una desjerarquización de los mismos, sino la necesaria elección de una de las variables más relevantes desde

'Sobre el proceso energético colombiano, ver Gerhard Drekonja Kornat, Co. lombia. Polttica Exterior (Bogotá, Colombia, Universidad de Ios Andes-Fescol) 1982, Cap. TV "El poder negociador colombiano en el sistema energético interracional".

La politica petrolera del gobierno militar brasileño a partir de 1964 es analizada por Alberto Tamer, en Petróleo: O Preço da Dependencia. O Brasil na crise mundial. (Rio de Janeiro, Editora Nova Fronteira, 1980).

El caso argentino consiste, en síntesis, en un distorsionado perfil de consumo, basado en un $70 \%$ de petróleo en el consumo total, (mientras que la proporción de los recursos comprobados es de $65 \%$ de gas y sólo $35 \%$ de petróleo). A Y.P.F., la empresa estatal, se le obliga a vender este petróleo a las refinerias a un precio cinco reces menor que el del mercado internacional. De lo que recibe la Empresa, la mayor parte va al Estado, como impuestos. Esta situación torna imposible un manejo económicamente adecuado. La Empresa, para poder subsistir económicamente, fue obligada por el Ministro de Economía, Martf́nez de Hoz, a contraer préstamos en dólares, en el exterior. La deuda externa de Y.P.F. alcanzó a 12.000 millones de dólares en 1981 (o sea el $60 \%$ de la deuda pública de ese momento). Se consideró entonces que y.P.F. habfa demostrado que no pođría cumplir sus tareas especificas y que varias de sus actividades debían pasar al sector privado. Ver, entre otros, "La batalla de la Energia", La Nación, Buenos Aires, 13. 6. 1982; "Demora la aprobación de los 14 contratos petroleros", Clarin, 3. 2. 1982; "Argentine, Oil and Gas: No eaxly salvation", Latin America Weekly Report, 29, October 1982, p. 9.

\section{$\left[\begin{array}{llll}1 & 3 & 3\end{array}\right]$}


el punto de vista de la política internacional. En este contexto, si bien sólo se efectuarán comentarios marginales al tema, la política energética nuclear latinoamericana, en virtud de sus implicancias políticas, económicas, tecnológicas y estratégico-militares, resulta de primordial importancia.

\section{EL ORDEN ENERGÉTICO MUNDIAL: RASGOS PRINGIPALES}

Entre 1973 y 1974 se produce lo que se denominó la "Crisis Mundial de la Energia". La cuadruplicación súbita de los precios del petróleo por parte de un grupo de los páses productores más importantes, nucleados en 1973 en la Organización de Países Exportadores de Petróleo (OPEP), para compensar una fuerte subvalorización de este recurso que se prolongaba desde principios de la década del sesenta ${ }^{6}$, causó un fuerte impacto en un sistema económico internacional que ya revelaba una seria parálisis de crecimiento, caída de inversiones y aumento de la inflación. La crisis energéti$\mathrm{ca}$, en consecuencia, se inserta en un contexto de elementos de mayor significación -el proceso inflacionario en los Estados Unidos y Europa Occidental; Ia pérdida de competitividad de la economía norteamericana frente a Europa Occidental y Japón y otros factores recesivos- que afectaban ya a principios de la década del setenta a la economía mundial.

La crisis energética se prolonga, con signos opuestos, hasta nuestros días (en 1979, reducción temporal de la producción y aumento de precios; durante 1981-1982, existencia de un excedente de ofexta y a principios de 1983, significativa reducción de los precios), transmitiendo sus efectos al plano político, económico, socio-cultural, tecnológico y estratégico-militar. No constituye la causa sino una manifestación - tal vez, decisiva- de la crisis estructural de un modelo de crecimiento económico basado en el uso intensivo de petróleo barato, sobre el cual se asentó la organización y el desarrollo del sistema global a partir de la reestructuración a que da lugar la Ir Guerra Mundial.

La crisis energética contribuye a generar importantes cambios en la economía internacional y en el régimen mundial de distribución del poder. Se intensifican las tensiones Este-Oeste, particularmente en el área del Golfo Pérsico y aumentan significativamente los diferendos internos entre los principales actores de Ia Organización para la Cooperación y el Desarrollo Económico (ocDE) en cuanto a la coordinación de la política energética, generándose crecien-

${ }^{\theta}$ En la década del sesenta los países de la opep intentaban sin éxito elevar sus beneficios más allá de un dólar por barril, mientras que las compañías transnacionales petroleras vendian el petróleo en Europa (ya industrializado), a valores comprendidos entre 12 y 14 dolares por barril. Ver, Ali M. Jaidah, "The pricing of petroleum", en Papers on the Economic of Oil, edit. by Mahmoud Abdel-Fadil (Kuwait, OAPEc, Oxford University Press, 1979) p. 61. 
te competencia por la obtención de seguridades en la provisión del petróleo. También se establecen importantes diferencias entre exportadores e importadores netos, en cuanto a la disposición de grandes recursos financieros por una parte y un grave incremento de los déficit de balanza de pagos y de cuenta corriente por la otra, que se traduce en un incremento de la deuda externa de los países importadores.

La crisis energética se inserta en un contexto recesivo con bajas tasas de crecimiento del producto en las economías industrializadas, basado en factores estructurales y en políticas económicas inadecuaclas, tanto en las potencias industriales (caracterizadas por un consumo irracional y excesivo de energía) como en los países en desarrollo, que intentaron adoptar un modelo articulado sobre el aprovechamiento de fuentes de energía barata y sin limitaciones, imitativo del de los actores industrializados. Ello permitió a un segmento de su población alcanzar un estilo de vida de alto consumo, en paridad con las sociedades más avanzadas, pero resțingió el acceso de la mayor parte de sus sociedades a condiciones de vida dignas y provocó graves distorsiones en la orientación y viabilidad del desarrollo nacional.

En particular, los países latinoamericanos debieron enfrentar un alto grado de proteccionismo en sus mercados de exportación; el incremento del valor de las manufacturas; la caída en el precio de los productos básicos; altas tasas de interés en los mercados intexnacionales de capital y política de estabilización y ajuste de los países industrializados. Estos factores contribuyeron a provocar fuertes desequilibrios en sus balanzas de pagos y de cuenta corriente, que condujeron a un creciente endeudamiento externo para poder mantener tasas adecuadas ( $y$ en muchos casos mínimas) de crecimiento económico.

En cuanto al mercado mundial del petróleo, el periodo 19731983 se caracteriza por su alta inestabilidad y un cambio. relativamente rápido de los actores que controlan los precios y la producción. Desde 1973 hasta fines de la década la OPEP obtiene y ejerce este control. No obstante, la recesión económica mundial, los programas de conservación de energía y el desarrollo de nuevas fuentes energéticas realizadas por los países industrializados redujeron la demanda. A ello se sumó el surgimiento de nuevos productores fuera de la OPEP, y a una recuperación de la producción en algunos páses de la OCDE (ej.: en Estados Unidos, los yacimientos de Alaska).

La interacción de estos factores permite la aparición de importantes excedentes de crudo en el mexcado mundial y la rápida y considerable reducción de los precios del petróleo, provocando a principios de 1983 una pérdida efectiva de la capacidad de la opEP (probablemente, de manera temporal) para controlar el mercado. 
Carlos J. Moneta / E1 factor energético (hidrocarburos)_en las relaciones...

\section{LOS PROBLEMAS QUE ENFRENTA AMÉRICA LATINA EN EL GAMPO ENERGÉTICO: RASGOS PRINCIPALES}

Las décadas de 1980 y 1990 se plantean como un "período de transición" de un sistema basado fundamentalmente en el petróleo, a otro de carácter más pluralista, en el que se espera que jueguen papeles más importantes los hidrocarburos no convencionales y la sustitución de los hidrocarburos por fuentes no tradicionales de energía.

Durante este lapso y quizás, por un período de tiempo mayor, los hidrocarburos desempeñarán un papel fundamental en el balance energético mundial y en las posibilidades de desarrollo económico. La incidencia de todos los aspectos relativos a su descubrimiento, posesión, explotación, comercialización, distribución y consumo continuarán resultando vitales para los actores del sistema internacional.

\section{Problemas económicos y financieros vinculados a la energía}

En este contexto, América Latina registra graves contrastes. La región podría, en un futuro, obtener un grado adecuado de independencia en materia de producción y abastecimiento de hidrocarburos si adecuara su estilo de desarrollo a las nuevas circunstancias y modificara su actual balance energético. América Latina exporta la mayor parte de los combustibles que produce (aproximadamente, el $77 \%)$ a las potencias industriales occidentales, restando sólo un $23 \%$ para el uso interno de la región 7 . (Ver Cuadros 5 y 6 ), que se ve obligada a importarlos, con un enorme efecto negativo sobre la balanza de pagos, la cleuda externa y en general, sobre los recursos financieros disponibles para su desarrollo.

Las variaciones en las cotizaciones del petróleo han provocado grandes perjuicios, tanto a los países exportadores como importadores de este recurso. Cuando el precio del petróleo aumenta, también lo hace el déficit de la balanza de pago de los países importadores latinoamericanos, que deben atender el mayor peso de sus cuentas petroleras. Así, a modo de ejemplo, el pago de esta cuentา cubría el $40 \%$ de los ingresos de exportación del Brasil, a principios de los años ochenta. Si se observa la situación de los países menores de la región, en el caso de Costa Rica, los pagos de las importaciones de petróleo absorbían el $83 \%$ de sus ingresos de exportación (aproximadamente, 273 millones de dólares). Para la región en su conjunto, el incremento del déficit comercial debido al mayor precio del petróleo alcanzó el $42 \%$ en 19748 .

Los países exportadores netos de petróleo se beneficiaron con los

TBoletin Energético NP 13 (Quito, OLADE, octubre 1979) p. 103.

${ }^{8}$ Estudio Económico de América Latina, 1974 (New York, GEPAL) pp. 204-205. 
incrementos de precios durante la década del setenta, disminuyen. do su déficit de cuenta corriente, mientras aumentaba el de los importadores. La actual reducción del precio del petróleo coloca en situaciones sumamente críticas a países como MIéxico y Venezuela, que realizaron programas de desarrollo interno con perfiles de alto consumo, contando con que sus exportaciones de hidrocarburos permitirían cumplir con el alto nivel de endeudamiento externo. A los niveles actuales de precio (34 dólares el barril), la totalidad de las exportaciones petroleras de México deberían ser utilizadas sólo para pagar los compromisos anuales de su deuda.

Otros hechos que revisten particular importancia son el aumento de los costos de producción, la futura escasez de este recurso y la capacidad de afectar al crecimiento económico y la seguridad nacional que brinda el hecho de depender en alto grado de una sola fuente energética (América Latina es la región en desarrollo que más depende de las importaciones de petróleo, ya que el $50 \%$ de su consumo energético proviene de esa fuente; si se le suma el gas, esta cifra oscila entre el $75 \%$ y el $80,8 \%{ }^{9}$.

América Latina, como el resto de las regiones en desarrollo, deberá enfrentar durante las próximas décadas fuertes desequilibrios entre la oferta y la demanda de hidrocarburos; entre los excedentes de recursos petroleros y financieros y, la escasez de los primeros y la retracción en el flujo de los segundos hacia la región. En la década del ochenta se necesitará contar con 240 a 280 mil millones de dólares para satisfacer las necesidades de la expansión de la demanda energética latinoamericana ${ }^{10}$ (o sea, de 22 a 26 mil millones anualmente), de los cuales el $60 \%$ debe ser provisto en divisas externas.

Si estas enormes cantidades no pueden ser obtenidas (lo que parece harto difícil, dadas las magras perspectivas de crecimiento de la economía mundial), América Latina deberá importar más hidrocarburos. Esta alternativa también es crítica, dados los serios problemas de balanza de pagos que tiene la región. Obviamente, si la región no puede satisfacer sus demandas de energía, se reducirá su crecimiento económico y aumentará su dependencia financiera externa ${ }^{11}$. Ello demuestra la gravedad de los problemas económicos y financieros vinculados a la energía y su importancia en la política económica intrarregional e internacional a poner en práctica

'El desarrollo de América Latina en los años ochenta, Doct. E/GEPAL/G. 1150; E/GEPAL/CEGAN 5/L.3; (Santiago, Chile, CEPAL, 4. 2. 198I), pp. 15-16; las cifias ofrecidas por el Banco Mundial hacen ascender la cifra a $80,8 \%$ para 1985 . Ver, Petroleum and Gas Non-OPEC Developing Countries; 1976-1985, World Bank Staff Working Paper No 289 (Washington, D.C. World Bank, April 1978), Annex I, Page 1 .

${ }^{10}$ Cornelio Marchan, Lalin America Energy' Cooperation: Problems and Perspectives, Papel de Trabajo (Quito, OLADE, 1982), p. 15.

IIIbid, p. 16. 
Garlos J. Moneta / El factor energético (hidrocarburos) en las relaciones...

a) Las influencias tecnológicas. En el campo de la tecnología se presentan, como algunos de los obstáculos principales, la debilidad de la infraestructura científico-técnica con que se cuenta; los enormes recursos necesarios para su avance y fortalecimiento; la dependencia de bienes de capital importados para el sector energético; el grado de complejidad de algunas tecnologías y las dificultades existentes para establecer un régimen efectivo y adecuado de importación de tecnología ${ }^{12}$.

Los factores señalados en los párrafos precedentes permiten aprehender la magnitud y complejidad de los problemas a enfrentar y señalan áreas donde es posible y necesario desarrollar una acción compartida, ya que los países de la región no se hallan capacitados para enfrentar estos desafíos en forma individual.

b) Las heterogeneidades existentes entre los paises de la región. Desde el punto de vista sociopolítico y de su capacidad económica, las diferencias existentes entre los países de la región, en términos de tipos de regímenes políticos, grados de desarrollo económico, dotación de recursos, etc., han sido recogidas en la formulación de distintas categorías. Se señala así, por ejemplo, la existencia de regímenes autoritarios y democráticos; las heterogeneidades que se presentan entre los países mayores, medianos y menores de la región o entre aquellos considerados de desarrollo intermedio, en desarrollo y de menor desarrollo relativo, así como los distintos tipos de estructuras socioeconómicas, agrupadas en este caso bajo las denominaciones de paises agrarios, minero-extractivos o industrializados.

A este conjunto de categorías diferenciadoras debe sumarse otras, vinculadas a la desigual distribución de los recursos energéticos y de su consumo en la región. En cuanto a la distribución de los recursos, los países pueden ser clasificados en "países en desarrollo exportadores netos de petróleo" y "países en desarrollo importadores de petróleo" (ver Cuadro I). Esta distinción puede enriquecerse considerando la existencia de reservas, la realización de actividades de exploración, etc. (ver Guadros 2 y 3 ). Entre las asimetrías más importantes a destacar, se encuentran las siguientes:

b.1) Desigual distribución de las reservas energéticas en la región. Con los datos con que se cuenta actualmente, el 92\% del carbón se concentra en México, Chile y Brasil, mientras que el $89 \%$ del petróleo se halla en México y Venezuela. Sin embargo, esta estimación no tiene en cuenta el potencial de nuevas áreas, que pro-

12Jorge Sábato, "Recursos energéticos y dependencia tecnológica", Seminario Internacional Energia y Desarrollo (Quito, OLADE, 15-18. 7. 1980) p. 21; Marcelo García e Iván Molina, El problema energético y las perspectivas de la cooperación regional un América Latina, Papel de Trabajo (México, D.F. CEEsTEMr, 1982), p. 31. 
meten ricos hallazgos. Entre ellas, se deben citar los yacimientos offshore del Atlántico Sur, la Antártida y la Patagonia argentina.

El $80 \%$ del gas natural se halla concentrado en México, Venezuela y Argentina. Venezuela y Brasil poseen la mayor parte de los hidrocarburos no convencionales, mientras el $100 \%$ de las reservas de uranio hasta ahora conocidas se hallan en Argentina, Brasil y México. Por último, el $76 \%$ de la hidroelectricidad se distribuye entre Brasil, Colombia, Perú, Argentina y Venezuela ${ }^{13}$.

b.2) Heterogeneidades en el consumo de los paises latinoamericanos. No sólo en la región sino en el Tercer Mundo la distribución del consumo energético es altamente desigual. Así, tres cuartas partes del consumo del total de los países en desarrollo se halla concentrado en 16 naciones, de las cuales corresponden a América Latina más de un tercio (Argentina, Brasil, México, Venezuela, Colombia y Chile).

Asimismo, mientras Argentina, Brasil, México, Venezuela y $\mathrm{Gu}$ ba consumen anualmente más de una tonelada equivalente de petróleo per cápita, el resto de los países de América Latina sólo alcanzan en su mayoría a consumir un equivalente del 0,2 al 0,5 de toneladas de petróleos anuales. A su vez, Brasil y México suman el $70 \%$ del consumo energético de la región, mientras que por otra parte, la leña significa un $20 \%$ del total de la energía consumida ${ }^{24}$. (Ver Cuadro 4).

b.3) Asimetrias en los niveles de bienestar social. Aproximadamente un tercio de la población latinoamericana, localizada en las zonas rurales y vinculadas a actividades de bajo nivel de productividad, permanecen fuera del circuito de consumo de la energía comercial, dependiendo básicamente de la leña y el carbón para satisfacer sus necesidades primarias.

b.4) Asimetrias en la producción. En cuanto a la producción de energía, los hidrocarburos, con el $16 \%$ del total de las reservas, suministran el $60 \%$ de la energía primaria, concentrándose su producción en Venezuela y México, mientras que la energía hidroeléctrica, a la cual le corresponde el $69 \%$ de las reservas totales cubre menos del $5 \%$ de la oferta total. Por último, el carbón mineral con el $26 \%$ de los recursos, sólo contribuye con el $2 \%$ de la oferta regional ${ }^{15}$. Estos datos certifican las distorsiones del perfil de consumo latinoamericano, basado esencialmente en los hidrocarburos.

${ }^{13}$ Ver PLACE (Quito, OLADE, 1981), pp. $87-98$ y Jorge Trenova, "El desarrollo del sector energético de América Latina entre 1950 y 1976", en H. Muñoz, Comp, Desarrollo Energético en América Latina y la Economia Mundial (Santiago de Chile, Editorial Universitaria, Universidad de Chile, 1980).

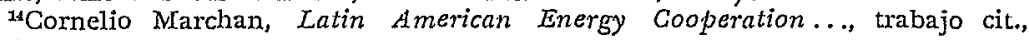
página 12.

${ }^{15}$ Alternativas energéticas en América Latina, (Quito, OLADE-PNuMA, octubre 1979) . 
Carlos J. Moneta / E1 factor energético (hidrocarburos) en las relaciones...

c) Bajo aonsumo energético y necesidad de su expansión regional. Los indices de consumo regional latinoamericano son relativamente bajos si se los compara con el resto del mundo. Alcanzan un $5 \%$ del consumo mundial y equivalen aproximadamente al $10 \%$ del consumo de los países industriales. Por ejemplo, un crecimiento del producto bruto del 3,5 anual requerirfa un aumento del $60 \%$ de la demanda energética. Ello implica que América Latina no va a poder reducir su consumo de energia. Por el contrario, para incrementar su desarrollo debe aumentar significativamente su consumo energético, si bien debe hacerlo de una forma más proporcionada y adecuada a su dotación de recursos ${ }^{16}$.

d) Critica situación de los paises imprortadores de menor desarrollo relativo. Los datos precedentemente mencionados señalan la gravedad de la situación para los países menores de la región (ver Cuadro 4), en los cuales su bajo nivel de desarrollo se halla estrechamente rinculado con el consumo reducido de energía. Estas economías, que carecen prácticamente de defensas externas, no tienen medios para afrontar la crítica recesión internacional e intentan neutralizar parte de sus compromisos externos mediante una reducción del ya muy limitado consumo de energía, con efectos involutiros sobre su nivel de desarrollo.

e) Creciente dependencia de las expontaciones petroleras como fumte principal de los ingresos para los países exportadores. En los países latinoamericanos exportadores, sean miembros o no de la OPEP, se registra una clara tendencia a que las exportaciones petroleras se constituyan en el único factor dinámico generador de ingresos externos significativos. En el caso de Venezuela, más del $70 \%$ de los ingresos externos en 1980 correspondieron al petróleo, mientras que en ese mismo año el petróleo significó el $68,1 \%$ del valor de las exportaciones mexicanas ${ }^{17}$. Esta alta dependencia del petróleo como fuente de ingresos pone en peligro los intentos de materializar un desarrollo equilibrado de los sectores agrícola e industrial, pudiendo conducir a una estructura económicosocial de "monocultivo petrolero".

2. Los recursos energéticos como factor de conflicto en las relaciones externas en los paises latinoamericanos.

El control de los hidrocarburos, junto al interés por otras materias

${ }^{10}$ Datos de estudios realizados por OLADE, cit. en Cornelio Marchan Latin American Energy)..., trabajo cit. p. 13.

${ }^{2 i V e r}$ "Los problemas actuales de las relaciones comerciales México-Estados Unidos", Informe Relaciones México-Estados Unidos, Vol. 1, No I (México, D. F., CFrstem, octubre de 1981), p. 91. Para Venezuela, ver Sergio Bitar y Eduardo Troncoso, "Petróleo e industrialización. La experiencia venezolana, 197:31980", Comercio Exterior, Vol. 32, No I1, noviembre de 1982, p. 1220. 
primas y recursos considerados estratégicos, constituye una de las causas principales de tensiones y conflictos con potencias extrarregionales, actores transnacionales $y$ actores internacionales.

Si bien en el primer caso los problemas de aprovechamiento de los recursos se hallan sumidos en un contexto más amplio, que responde a conflictos de carácter hegemónico y a antagonismos ideológicos a nivel mundial, intereses vinculados al papel económico y estratégico de los recursos energéticos han constituido causa de conflictos con los Estados Unidos y con otros actores occidentales industrializados; entre los Estados Unidos y potencias europeas (ej.: diferencia europeo-norteamericanas en la coordinación de sus politicas energéticas frente a la OPEP), así como entre los Estados Unidos y la Unión Soviética (ej.: "la guerra del gasoducto"; política de ambas potencias en Medio Oriente).

Con respecto a América Latina, cabe citar, entre otros, los problemas vinculados al papel de los hidrocarburos en la polf́tica bilateral entre Estados Unidos y México y entre Estados Unidos y Venezuela; las tensiones germano-estadounidenses al apoyar Alcmania Federal con tecnología y financiamiento un desarrollo tecnológico nuclear relativamente independiente del Brasil y, la preocupación norteamericana con respecto a una creciente vinculación de Argentina con al Unión Soviética, de la cual derivan ciertos avances tecnológicos y materiales necesarios para el desarrollo de su capacidad nuclear ${ }^{18}$.

En cuanto a los conflictos con actores transnacionales, el caso que obviamente surge en primer lugar es el de las empresas transnacionales de petróleo con los gobiernos latinoamericanos y sus vinculaciones con los actores subnacionales en cada país. La política de nacionalización de los hidrocarburos que se desarrolló en América Latina produjo un amplio número de importantes conflictos en este sector (ej.: procesos de nacionalización en México, Vemezuela, Bolivia, Argentina, Perú, etc.) Estos conflictos han ampliado enormemente su espectro, centrándose ahora ya no en la propiedad de los recursos, sino en la tecnología y el financiamiento para su desarrollo, así como en los procesos de industrialización, comercialización y marketing ${ }^{19}$.

\footnotetext{
${ }^{2}$ Argentina ha recibido cinco toneladas de agua pesada de la urss y equipos industriales para la fábrica de tubos de zircaloy para la fabricación de combustible atómico. Durante 1982 se estuvo estudiando la posibilidad de efectuar un acuerdo con la uRss para la asistencia técnológica. Ver, entre otros, "El liderazgo atómico de la Argentina", Clarin, 28. 12. 1981, p. 5. Para un tratamiento del tema, ver Garlos J. Moneta, "El conflicto de las islas Malvinas: su papel en la polftica exterior argentina $y$ en el contexto mundial", Esludios Internacionales, Univ. de Chile, Año xv, octubre-diciembre 1982, pp..396-398.

${ }^{10} \mathrm{~A}$ modo de ejemplo, en Venezuela, donde la nacionalización de los hidro. carburos se realizó en 1976, surgieron durante los primeros años de la década del ochenta importantes problemas politicos por las condiciones incluidas en
} 
Por último, la orientación vigente en algunos de los organismos de las Naciones Unidas por intermedio de sus burocracias y de las posiciones adoptadas por una parte de los países del Tercer Mundo, tendientes a internacionalizar la propiedad de los recursos en ciertas zonas y a extender su ámbito de control (ej.: Medio Ambiente) y de coordinación del relevamiento y explotación de los recursos, ha conducido no sólo a actividades cooperativas con los países sino también a enfrentamientos directos con Estados de América Latina ${ }^{20}$.

a) Vulnerabilidad politioo-económica creciente de los paises exportadores netos de hidrocarburos, en función de la evolución del mercado petrolero internacional. Teniendo como uno de los propósitos el disminuir su dependencia del mercado norteamericano, los principales países exportadores latinoamericanos realizaron importantes esfuerzos para diversificar sus mercados externos. México disminuyó sus exportaciones de hidrocarburos a los Estados Unidos de un $84,2 \%$ del total de sus exportaciones en 1979 a un $49,8 \%$ en $1981^{21}$, desplazando esos volúmenes de crudo a Japón, Gran Bretaña, Francia, Israel y Canadá, en el grupo de países desarrollados; a varios países de Centroamérica y el Caribe (junto con Venezuela), en virtud del Acuerdo de San José y, a Brasil y Uruguay. Venezuela, por su parte, realizó una intensa campaña para aumentar sus ventas en Europa Occidental (particularmente en Alemania Federal) y diversificar su cartera de compradores, vendiendo aproximadamente un millón de barriles diarios a los Estados Unidos del total de 1,6 a 1,7 millones de barriles diarios de sus exportaciones durante $1982^{22}$.

Tanto en México como en Venezuela, se pensó que el hecho de que los Estados Unidos fuera el importador neto más importante de hidrocarburos para ambos países, permitiría contar con un elemento de negociación en el conjunto de las relaciones económicas bilaterales con la superpotencia (ej.: ]a "garantía de suministros")

contratos con empresas norteamericanas, entre ellos, la Betchel, para estudios relacionados con la exploración de la faja petrolera del Orinoco.

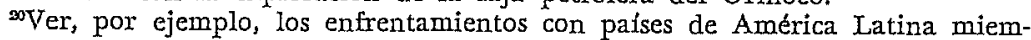
bros del Tratado Antártico en, Carlos J. Moneta, "Antärtica, Latin America, and the International System in the 1980s. Toward a News Antarctic Order?" Journal of Interamerican Studies and World Affairs. Vol. 23, No 1, February 1981.

"Ver, "Los problemas actuales de las relaciones comerciales México-Estados Unidos". Informe Relaciones México-... public. cit. p. 91.

${ }^{22}$ Carlos Guerón, "La conexión norteamericana. Relaciones Estados UnidosVeuezuela después de Malvinas", en Carlos Moneta, Compilador, Las relaciones entre América Latina y los Estados Unidos. Problemas y perspectivas. (Buenos Aires, título provisorio: obra a publicarse durante 1983), pp. 29-30 del trabajo. ${ }^{23} \mathrm{Ver}$ "La vulnerabilidad de los energéticos como arma de negociación de México", Informes Relaciones México ..., public. cit., pp. 98-99. 
Se esperaba que su influencia alcanzara aún a cubrir los intereses político-estratégicos divergentes (ej.: utilización de los hidrocarburos por México y Venezuela en el Caribe y Centroamérica como instrumento de política exterior, frente al proyecto de la "Cuenca del Caribe" de la administración Reagan).

Este supuesto de independencia creciente se cumplió en algunos aspectos parciales (no por ello menos importantes), permitiendo cierto despliegue autonómico durante los años de auge del mercado petrolero internacional. Guando éste pierde su fortaleza y caen los precios, en un contexto de recesión global generalizado, la mayor parte de los miembros de la OPEP (con excepción de algunos productores del Golfo Pérsico) y los países en desarrollo exportadores que no pertenecen a la Organización, sufren una severa reducción de su capacidad de ejercer influencia en el sistema internacional.

En el caso de México y Venezuela, el gigantesco crecimiento de su deuda, concentrada en préstamos de la banca privada norteamericana ${ }^{24}$ y en menor grado, en aportes europeos y japoneses, implica en primer lugar, la necesidad de someterse a una rígida disciplina financiera ortodoxa a través de los organismos financieros internacionales (Fondo Monetario Internacional), según los criterios de la banca privada con origen en los países industrializados.

Indirectamente, sin embargo, las limitaciones que surgen para la puesta en marcha de una política exterior de orientación independiente son aún mayores. Los países deben adecuar lo sustantivo y concreto de su política exterior a la nueva situación de crisis. Ello significa no sólo aceptar en mayor grado los requerimientos de la contraparte en el campo económico, aun cuando resulte inconveniente para los propios intereses, sino también tener que ceder posiciones en el plano político y estratégico. EI hecho de utilizar el petróleo como "motor del desarrollo económico", con caracteres hegemónicos, y la condición estratégica del producto, conduce a que no poder obtener los beneficios esperados de este recurso, genere situaciones condicionantes que desbordan ampliamente el plano económico.

b) El papel de los exportadores latinoamericanos en el mercado mundial: las relaciones con la OPEP. En otro orden, las interacciones entre los miembros de la OPEP también imponen restricciones mutuas en la libertad de poner en práctica determinados aspectos de

\footnotetext{
2Según datos proporcionados por el Secretario de Estado de los Estados Unidos, Schultz, la deuda con los bancos norteamericanos es la siguiente: en México: sobre un total de 64.400 millones de deuda, se debe a bancos norteamericanos 24.300 millones de dólares. Venezuela debe 11.000 millones a bancos de los Estados Unidos, sobre un total de 27,200 millones de dólares, cable UPI, Washington, D.C., 24. 2. 1983, cit. en "Deuda: Bomba del Tercer Mundo", El Nacional, Caracas, 25. 2. 1988.
} 
la política energética (fijación de precios y niveles de producción y exportación, etc.). Si bien ello constituye un requisito imprescindible para otorgar viabilidad a los objetiros perseguidos por la Organización, en situaciones de crisis como la que se enfrenta, surgen con toda intensidad los conflictos de intereses.

La negativa venezolana a aceptar la cuota de producción impuesta por la OPEP a mediados de 1983 en función del "interés nacional"25 (situación que se repitió con varios países africanos); los desacuerdos posteriores sobre los precios de los distintos tipos de crudo y la quiebra por Nigeria, en febrero de 1983, de los precios de referencia fijados por la Organización (a la cual clebe sumarse la "flotación" de los precios del petróleo ecuatoriano) ${ }^{26}$, constituyen situaciones en las cuales los miembros latinoamericanos de la OPEP deben desarrollar cruciales, imaginativos y delicados ejercicios de política exterior. La "componente energética" constituye un elemento vital en la ecuación de sus políticas externas, pero también así resulta en el caso de los importadores netos (ej.: Brasil, pafses centroamericanos) $y$ en el de los exportadores que no pertenecen a la Organización (México, en primer lugar, pero también vale para los casos de Bolivia, Trinidad-Tobago y Perú).

En este contexto, cabe destacar el papel desempeñado por Venezuela, miembro promotor y fundador de la opep, desde los inicios de la Organización $y^{\prime}$ muy particularmente, los intentos de mediación entre las partes en disputa y la búsqueda de una articulación de posiciones y coordinación de políticas en el seno de la $\mathrm{Or}$ ganización que realizara este país durante los primeros años del ochenta ${ }^{27}$.

México, en su carácter de tercer exportador y cuarto o quinto país en reservas ${ }^{28}$, desempeña un rol cada vez más importante en

-Ner declaraciones del Ministro de Energía y Minas de Venezuela, Humberto Calderón Berti, en la Cámara del Petróleo: "Yo asumo la responsabilidad ante el país por el aumento de la producción petrolera", El Universal, Caracas, 25. 7. 1982.

nocuador puso a flotar el precio del petróleo", El Nacional, Caracas, 9. 2. 1983.

*Venezuela desempeñó un importante papel cualitativo en la conducción de la política de la OPEP desde la fundación de la Organización, pese a que su importancia relativa como productor fue disminuyendo. Tras el cese de electivividad el 30 de junio de 1982 de la decisión de la opep sobre la distribución de cuotas de producción, Venezuela incrementa su producción en 300.000 barriles diarios, justificando su acción en la necesidad de cumplir con compromisos de venta previamente asumidos. Esta polftica despierta duras críticas en el seno de la Organización. Posteriormente, al producirse la crisis de febrero de 1983 (quiebra unilateral por Nigeria de los precios fijados por la opep), Venezuela desarrolla una intensísima gestión diplomática negociadora, entre los miembros de la Organización, acordando además líneas de acción común con México. Ver, por ejemplo, "Venezuela y México actúan para ordenar los mercados", El $N a-$ cional, Caracas, 24. 2. 1983.

2s $y{ }^{20}$ México ha fijado hasta $1983,1.500 .000$ barriles diarios como tope de sus 
el mercado mundial de hidrocarburos. El hecho de no pertenecer a la OPEP y poseer cierta capacidad "disruptiva"20 de los acuerdos de regulación del mercado que intenta concretar la Organización, otorga mayor relieve a su política energética externa y en particular, a sus relaciones con ella. En el marco latinoamericano, dado que Venezuela y México compiten por la venta de petróleo en el mercado norteamericano, la búsqueda de entendimientos y fijación de reglas de juego resulta siempre necesaria para ambos países.

La relación con la OPEP no ha sido fácil. México no se unió en el pasado a la Organización por varios motivos (ej.: deseo de mantener independencia en su política exportadora; implicancias sumamente negativas que tendría esta acción en el contexto de las relaciones mexicano-norteamericanas), pero en términos generales, siguió y usufructuó la política de precios fijada por la OPEP, cortejando la idea de su ingreso a la Organización sin asumir compromisas al respecto. No obstante, durante 1982 vendió su petróleo "tipo istmo" a 32,50 dólares el barril, frente a los 34 dólares fijados por la OPEP para el crudo arábigo. La posterior caída de los precios a principios de 1983 ubica a México en una posición cautelosa, efectuándose estrechas consultas con los miembros de la Organización y en América Latina, con Venezuela, sobre la actitud a adoptario, ya que el abrupto descenso de precios afecta por igual a los países exportadores, pertenezcan o no a la OPEP.

La modificación, perjudicial a sus intereses, del mercado mundial, ubica a México ante una crucial alternativa: a) formular y poner en práctica una política de gradual acercamiento $y$ eventual ingreso a la Organización ${ }^{31}$ para preservar sus ingresos a largo plazo; b) actuar como ariete y contribuir, sin desearlo, a una guerra de precios, asegurando su participación, en las mejores condiciones actualmente posibles en el mercado norteamericano, con el propósito de salvar la gravísima situación de endeudamiento externo y de crisis económica que enfrenta en el corto plazo. El margen real de maniobra para esta disyuntiva es estrecho, por los factores mencionados en el punto anterior, que ubican hoy a México en una par-

exportaciones. Además, según informes internos técnicos, sería difícil aumentar sus exportaciones a 2.000 .000 barriles diarios hasta mediados de 1983, La producción total se aproxima a los 2.750 .000 barriles diarios, destinándose 1.250 .000 barriles al mercado nacional. Sin embargo, los estudios realizados en los Estados Unidos (ej.: el estudio de la cla), prevén una capacidad de producción de 4,5 a 6 millones de barriles diarios para 1985. Si una parte sustantiva de esta capacidad se volcara al mercado mundial, ejerceria una enorme influencia en las condiciones de regulación de la oferta.

sorvenezuela y México actúan para regular los mercados...", art. cit. (Ver nota No 27) .

"Ver, entre otros, "Mexican oil industry report urges stranges Opec link", Latin America Newsletters, 12 November 1982. Sin embargo, durante conversaciones con miembros de la actual administración mexicana, se consideró poco probable que por el momento se avance hacia un ingreso en la opep. 
ticular situación de dependencia dentro del marco de su tradicional subordinación económica a los Estados Unidos, esquema que aún en el período de auge de las exportaciones petroleras no logró modificar en lo sustancial ${ }^{32}$.

c) La vulnerabilidad politico-económica de los paises importadores netos de hidnocarburos en función de la evolución del sistema económico internacional. A modo de ejemplo, puede citarse los casos de Brasil, uno de los países mayores de la región, y de Costa Ri$\mathrm{ca}$, que bien puede representar la situación de la mayor parte de los países centroamericanos.

En estos dos países, la cuenta petrolera, si bien ahora desciende, aún representa un porcentaje muy importante de los pagos por importaciones ${ }^{33}$. Las características previamente comentadas de la recesión internacional conducen a una disminución de la dimensión autonómica de sus políticas exteriores. Así, tras el viaje del Presidente Reagan al Brasil y la extensión de un préstamo de corto plazo por mil cien millones de dólares ${ }^{34}$, a lo que se suma un aval de Estados Unidos ante el Fondo Monetario y la banca privada internacional, se produce un rápido giro de la posición brasileña en algunos temas claves de las negociaciones del GATr. Brasil, país que ocupaba una posición de liderazgo en la oposición del grupo latinoamericano de Ginebra a la inclusión del tema de servicios en las negociaciones a celebrarse durante la Reunión Ministerial del GATr en 1982, acepta posiciones norteamericanas contra las cuales había luchado hasta entonces con singular vigor. Lo expuesto no pretende establecer una simplista relación casual directa, sino señalar nuevamente las restricciones y condicionamientos que impone la actual coyuntura económica mundial.

Por su parte, Costa Rica modifica drásticamente la posición de su polftica exterior con respecto a Centroamérica con el cambio de gobierno. La asunción de Monge al poder, que coincide con una grave crisis de la economía costarricense, conduce a un total acercamiento a la administración Reagan, en la búsqueda de asistencia

\footnotetext{
${ }^{32}$ Entre los numerosos trabajos sobre el tema, ver los artículos publicados por "Foro Internacional" (E1 Colegio de México), durante los años 1979-1983. Para una sintesis de la situación actual, ver " $\mathrm{La}$ vulnerabilidad de los energéticos como arma de negociación...", art. cit.

${ }^{3} \mathrm{Las}$ importaciones brasileñas de petróleo durante 1982 se acercaron a los 10.000 millones de dólares, Cables IPS, "Ahorro de cien millones de dólares en las importaciones de petróleo", 6. 6. 1982; "Primeros resultados de la estrategia energética", julio 1982.

${ }^{34}$ Sobre la dimensión crítica de la deuda externa brasileña y los condicionamientos que impone a la política interna e internacional, ver André Lara Resende, "A crise no mercado internacional de crédito e o endividamente externo do Brasil: una avaliaçao da situaçao atual", documentos de trabajo, Departamento de Economia Pontificia Universidad Católica de Río de Janeiro, enero de 1983 .
} 
económica y financiera. 'Como contrapartida, el nuevo gobierno de Costa Rica adopta posiciones coincidentes con los objetivos norteamericanos en Centroamérica y el Caribe, adaptándose a cumplir funciones en el marco geopolítico diseñado por los Estados Unidos para la subregión.

\section{EL PAPEL DE LA ENERGÍA EN LA POLÍTICA INTRALATINOAMERICANA}

Los hidrocarburos - particularmente el petróleo- así como otros recursos energéticos (ej.: los hídricos), jugaron papeles importantes en la modificación del grado de viabilidad económica, la capacidad de proyección política y dimensión estratégica de muchos de los países de América Latina. Hasta hace una década atrás, cuando el costo del petróleo no incidía de manera esencial en las balanzas externas, las distinciones entre "países exportadores netos de petróleo y países importadores netos" -que hoy significan diferencias sustantivas en la capacidad de acción en el plano interno e internacionalno existían o eran mínimas. Si bien el petróleo constituf́a ya la columna vertebral del crecimiento económico de países como Venezuela y México, este elemento era un factor más en la dotación de recursos económicos de los países de la región.

El boom petrolero contribuyó, de manera significativa, a alterar esta situación. El incremento de recursos financieros - susceptibles de ser transformados en recursos políticos- favoreció el crecimiento de alguno de los países mayores de la región. Así, se percibe el crecimiento de la estatura político-estratégica de México y Venezuela (ej.: propuesta del "Nuevo Orden Económico Internacional", de México y la "Diplomacia de Proyección" de orientación autonómica, venezolana). Como contrapartida, se observa el inicio de los grandes problemas de Brasil durante los últimos años de la década del setenta, a través del explosivo aumento del costo de sus importaciones de petróleo ${ }^{35}$.

Por otra parte, el desarrollo y la explotación de fuentes no tradicionales de energía que implican un alto agregado tecnológico - tal el caso de la energía nuclear, susceptible además de aplicarse militarmente- permite también un incremento del prestigio y la estatura estratégica de algunos países latinoamericanos (Argentina, Brasil), si bien ello no necesariamente se traduce en la disposición de mayores recursos económicos.

El impacto de los cambios que presenta el régimen energético internacional durante la última década ha afectado notablemente a las relaciones intralatinoamericanas. Tanto la posesión como la carencia de algunos de estos recursos se convirtieron por sí mismas en

${ }^{*}$ Brasil importaba 800.000 barriles diarios en 1973 a un costo de 600 millones de dólares. En 1979, la importación de 960.000 barriles diarios requería casi 7.000 millones de dólares. 
causas de cooperación y de conflictos bilaterales o intrarregionales. Disputas sobre la propiedad de espacios geográficos que contenian cantidades significativas (comprobadas o potenciales) de hidrocarburos y en menor grado, de hidroelectricidad, integraron en forma destacada la ecuación de intereses en competencia entre dos o más países de la región, así como también formaron parte de conflictos con potencias extrarregionales.

Es dable observar que los conflictos por el control y la posesión de materias primas y recursos naturales (vinculados generalmente a problemas territoriales), se van incrementando en América Latina. Entre éstos, aparecen como predominantes aquellos relacionados con los recursos energéticos.

Entre los más importantes, cabe citar el diferendo entre Argentina y Chile en la zona del Canal del Beagle y su ámbito de influencia, que si bien comprende a otros factores (comunicaciones y transporte marítimo), se basa principalmente en la disputa por el acceso y control de grandes recursos potenciales de hidrocarburos en el Atlántico Sur Austral. En el sector austral se presenta también entre estos dos países e Inglaterra un conflicto sobre un sector de la Antártida, en el cual los tres Estados alegan poseer soberanía ${ }^{36}$. Esta zona del territorio antártico es y será, en función de su cercanía relativa al continente sudamericano; las más fáciles condiciones de acceso que ofrece (Península de San Martín) y los recursos ictiológicos y de hidrocarburos que se estima posee, una causa muy probable de futuros conflictos con un número mucho mayor de paises, tanto de la región (ej.: Brasil, Uruguay) como no pertenecientes a ella ${ }^{37}$.

El no resuelto conflicto de los archipiélagos de Malvinas, Georgias e Islas Sandwich del Sur entre Argentina e Inglaterra-que eventualmente puede envolver a Chile y a otros países regionales y extrarregionales- si bien gira alrededor de la posesión de las islas, tiene su foco de interés real en la capacidad de la zona económica exclusiva oceánica que las circunda. El área frente a Malvinas y la zona adyacente al sur de la costa patagónica argentina presentan vastas mesetas submarinas con ricos perfiles petrolíferos, cuya verificación aún no es definitiva ${ }^{38}$.

Para completar el cuadro en el Cono Sur, el conflicto entre Argentina, Brasil y Paraguay por el aprovechamiento de los recursos hidroeléctricos del Alto Paraná (que incluyó fundamentalmente a la gigantesca represa brasileño-paraguaya de Itaipú), constituyó uno

\footnotetext{
saSobre el tema, ver Carlos Moneta, "Antartic, Latin America and the...", art. cit.

mibid.

खver, Carlos Moneta, "El conflicto de las islas Malvinas: su papel en la poIftica..." art, cit.
} 
de los motivos centrales de serias tensiones entre estos países desde 1965 hasta principios de la década del ochenta ${ }^{39}$.

Hacia el norte, la limitación de la frontera colombo-venezolana en el Golfo de Venezuela (Archipiélago de los Monjes), responde en último término a un conflicto por la posesión de los recursos petroleros submarinos de esta zona. De igual manera, las tensiones y problemas a que se halló asociado el nacimiento de Belice a la independencia, en 1981, se hallan estrechamente vinculados con los intereses petroleros de Gran Bretaña primero y luego de Guatemala ${ }^{40}$.

Los ejemplos mencionados señalan que los conflictos territoriales existentes en la región, aún mantienen las características formales de los enfoques decimonónicos (deseo de obtener el reconocimiento de soberanía y la posesión formal del territorio, junto con los símbolos de su posesión-capacidad de ejercer policla, servicios, bandera, etc.-). En este sentido, responden en mayor grado a los contenidos tradicionales de los enfoques geopolíticos predominantes en América Latina sobre el Estado-nación ${ }^{41}$.

En la práctica, en la medida en que algunos países latinoamericanos van incrementando su capacidad de actuar en los marcos regional e internacional, estos conflictos deberian comenzar a ser percibidos (y en algunos casos, así lo es) bajo una nueva óptica, más realista y pragmática, que tenga en cuenta las tendencias actuales del sistema internacional. Bajo este segundo enfoque, lo que interesa principalmente es la capacidad de ejercer control sobre el aprovechamiento del recurso, resultando relativamente secundarios los aspectos y modalidades tradicionalmente legitimadoras.

La aplicación de esta perspectiva - a diferencia de la anteriorpermitiria, mediante negociaciones que tuvieran en cuenta los beneficios económicos y politicos a alcanzar, un aprovechamiento mutuamente beneficioso y no excluyente de los recursos (para lo cual siempre se hallarán las fórmulas jurídicas adecuadas), frente a la alternativa de continuar indefinidamente el conflicto o de definir-

\footnotetext{
${ }^{a} \mathrm{E}$ l conflicto central giró en derredor del régimen jurfdico de exploración, uso y conservación de los recursos hidricos a aplicar (y las modalídades de aplicación) en tramos sucesivos y compartidos del sistema hídrico de la Cuenca del Plata. La causa principal fue la disputa entre Argentina y Brasil por el aprovechamiento hidroeléctrico del potencial del Alto Paraná.

sover, "Esperanzador futuro petrolero espera a Belice". El Universal, Caracas, 22. 9.1981 .

"Casos que encuadran perfectamente en este comentario son los conflictos argentino-chileno sobre el Beagle y el sector antártico. EI conflicto argentinobrasileño sobre el aprovechamiento hidroeléctrico del Alto Paraná también unfa a la existencia de factores concretos y objetivos, serias distorsiones en la per-. cepción de cada acto sobre los objetivos e intenciones del otro. Al respecto, ver los trabajos de Stanley Hilton y Joseph Tulchin sobre la percepción de las intenciones argentina y brasileña desde Brasilia y Buenos Aires, en, Carlos Moneta, Joseph Tulchin, y otros, Geopolitica y estrategia del Atlántico Sur (Buenos Aires, Edit. Pleamar, 1983).
} 
Carlos J. Moneta / El factor energético (hidrocarburos) en las relaciones...

lo mediante el uso de la fuerza, generando fuentes de tensión bilateral o subregional y facilitando la acción disociadora extrarregional.

LA AGCIÓN GOOPERATIVA EN EL GAMTPO ENERGÉTICO DE LA POLf́TICA EXTERTOR LATINOAMERICANA

Frente a las dimensiones de conflicto planteadas, es necesario destacar los enormes avances realizados en la cooperación latinoamericana en materia de energía. La región está logrando, no sin tropiezos, articular una respuesta relativamente rápida y coherente a la crisis del régimen energético internacional. Esta respuesta abarca varios planos fundamentales:

\section{Organización Institucional}

En cuanto hace a la exploración y desarrollo de los recursos energéticos, se ha producido la creación y consolidación de organizaciones intergubernamentales y privadas a nivel regional (ej.: ARPEL -Asistencia Recíproca Estatal Latinoamericana y cIER-Comisión de Integración Eléctrica Regional); el tratamiento coordinado y conjunto de los problemas vinculados a la utilización de recursos energéticos y la organización y creación de nuevos mecanismos de cooperación multilateral entre países de la región.

2. Capacidad autonómica latinoamericana para el desarrollo de sus recursos energéticos.

Entre los factores favorables que se presentan, deben señalarse los siguientes: prácticamente todos los países de la región han nacionalizado sus yacimientos de hidrocarburos y poseen empresas petroleras estatales que cuentan con amplios recursos y experiencia técnica (particularmente México, Venezuela, Brasil y Ärgentina). De igual manera, se halla nacionalizada la producción de gas y el sistema de generación y distribución de energía eléctrica ${ }^{42}$.

En los países mayores de la región también existe una industria de bienes de capital que puede suministrar en parte el equipo para la industria energética, así como también se posee mano de obra calificada e instituciones de investigación y desarrollo tecnológico de alto nivel en los países mayores del área ${ }^{43^{-}}$que pueden liderar el proceso de formación de los cuadros científicos y técnicos necesarios.

\section{La creación de una Organización Latinoamericana de Energia}

Por último, en el plano de la coordinación de acciones entre los

"Ver, Jorge Sábato, "Recursos Energéticos y Dependencia Tecnológica", art. cit. p. 20.

sTbid. 
paŕses latinoamericanos en el campo de la energía, se crea en noviembre de 1973 por el Acuerdo de Lima, la olADE. Su propósito principal es la integración, protección, conservación, uso racional, comercialización y defensa de los recursos energéticos latinoamericanos.

Los objetivos y la amplia membresía de la Organización (más de 25 miembros de América del Sur, América Central y el Caribe) han permitido importantes avances en la década de su existencia. Además de los objetivos relacionados con la creación de organismos financieros para el desarrollo de proyectos energéticos; la solución de los problemas de transporte; la creación de un mercado energético latinoamericano; la promoción de la cooperación técnica y cientifica y otras medidas de esta naturaleza, OLADE establece criterios y objetivos en el campo de las políticas exteriores de sus miembros.

Así, la Organización promueve la solidaridad entre los Estados miembros frente a todo tipo de acciones, sanciones y coerciones externas que surjan como resultado de medidas adoptadas para preservar y mantener los recursos energéticos al servicio de los planes y objetivos nacionales de desarrollo ${ }^{44}$. De igual manera, OLADE promueve y coordina negociaciones directas entre sus miembros para garantizar un flujo estable y suficiente de energía para el desarroIlo, así como la obtención de entendimientos cooperativos entre los Estados, para lograr un uso compartido de los recursos energéticos.

Asimismo, Latinoamérica organizó el Programa Latinoamericano de Cooperación Energética (PLACE), que tiene como propósito crear un instrumento que fortalezca a la OLADE y asegure el logro de sus objetivos $^{45}$, permitiendo incrementar la capacidad de acción conjunta en el marco internacional. En este sentido, constituye un compromiso político de los países de la región para adoptar acciones conjuntas y coordinadas, para superar la difícil situación actual y asegurar las condiciones de un desarrollo adecuado en el futuro.

Reconociendo la existencia de heterogeneidades politicas y socioeconómicas, tecnológicas y de posesión de recursos, se busca aprovechar esta heterogeneidad para lograr resultados más satisfactorios en la armonización de la producción, el uso de la energía y el desaxrollo económico y social; la diversificación e incremento de las fuentes de provisión energética y la racionalización de la producción y el uso de energía ${ }^{46}$. Ello implica una gigantesca tarea a realizar en materia de planeamiento de los recursos energéticos; su identificación y evaluación; aprovisionamiento, racionalización; cooperación tecnológica en la producción de bienes de capital; sis-

\footnotetext{
*Ver Objetivos, Convenio Constitutivo de la olAde (Convenio de Lima) 2. 11. 1973.

1Ver: Latin America Energy Cooperation Program (PLAGE) Report of the Committee of Minister to the twelth Meeting of Ministers (Santo Domingo, OLADE, November 13-15, 1981).

torbid.
} 
Carlos J. Moneta / El factor energético (hidrocarburos) en las redaciones...

temas de información energética; cooperación financiera y negociaciones energéticas internacionales ${ }^{47}$.

\section{La cooperación interinstitucional en el campo económico $y$ energético.}

En el diseño de los lineamientos estratégicos de este gran proyecto de cooperación latinoamericano, OLADE no ha estado sola, recibiendo el apoyo de otros organismos. Tal es el caso del Sistema Económico Latinoamericano (SELA), que en forma sistemática, a partir de la x Reunión de Ministros de la olade (Panamá, diciembre de 1978), sostuvo la necesidad de crear un Programa de Cooperación Energético Latinoamericano.

Este programa, dotado de un enfoque estratégico, debía lograr la autonomía energética regional, de manera tal de poner los procesos de desarrollo de los países latinoamericanos a cubierto de contingencias mundiales, coordinando en beneficio de los países de la región los inmensos recursos existentes ${ }^{48}$.

El SELA también diseñó un programa de acción, que bajo la óptica de la seguridad económica regional, adopte medidas específicas tendientes a reducir la vilnerabilidad externa de las economías latinoamericanas. Fueron seleccionadas como áreas prioritarias de cooperación, vinculadas, en cuanto corresponde a la energía, los alimentos; ciencias y tecnología; comercio exterior; financiamiento y transporte, información y comunicaciones ${ }^{49}$.

\section{Acuerdos y modalidades de cooperación entre los paises latinoamericanos.}

Los acuerdos de cooperación latinoamericanos en el campo energético son variados, creativos y de gran potencial. A modo de ejemplo, a principios de 1982 México, Brasil y Venezuela -los países con mayor desarrollo en materia petrolera- acordaron crear una empresa multinacional de petróleo (PETROLATIN), en el contexto de los objetivos de la OLADE y del PLAGE. Uno de los propósitos fundamentales de esta empresa sería el de contribuir a la exploración y explotación de los recursos energéticos de la región. La empresa surgirá gracias a los esfuerzos conjuntos de las empresas de hidrocarburos de México (PEMEX); del Brasil (PETROBRAs) y de Venezuela (PDVSA).

Otra experiencia, ya materializada, que trasciende el marco re-

"Ibid; ver también Cornerlio Marchan, "Latin American Energy...", trabajo cit., pp. 20-21.

${ }^{4 S} V$ Informe Anual de la Secretaría Permanente, docto. SP/CL/VIr.O/DT No 3 (Caracas, SELA, 1982, pp. 8 y 79-85.

${ }^{* D}$ Decisión No 125, Programa Bienal de Cooperación Regional, vir Consejo Latinoamericano, docto. CL/VIII.O/DF No I (Caracas, SELA, 25. 8. 82). 
gional por su importancia política y económica, es el "Acuerdo de San José", firmado en Costa Rica, en agosto de 1980, por los presidentes de Venezuela y de México. En virtud de este Acuerdo, ambos gobiernos deciden establecer un programa de cooperación energética para los países de Centroamérica y el Garibe.

Este Acuerdo, que beneficia a Barbados, Costa Rica, El Salvador, Guatemala, Honduras, Jamaica, Nicaragua, Panamá, República Dominicana y Belice, ha resultado crucial para los países centroamericanos, permitiéndoles hacer frente a su crítica factura petrolera. Al plantear el Presidente Reagan su "Plan de la Cuenca del Caribe", este Acuerdo constituyó un puntal de las posiciones sostenidas por México y Venezuela frente a los Estados Unidos.

Ambos países decidieron mantener el Acuerdo, que se renueva anualmente, sin incluir en él ningún tipo de restricciones en función de las posiciones ideológicas de los países recipendiarios, en abierto desacuerdo con el criterio de excluir a ciertos países de la región de los programas de asistencia de la Cuenca en virtud de su orientación política, mantenido por la Administración Reagan ${ }^{50}$.

En el marco regional son múltiples los ejemplos de cooperación y complementación económica en el campo energético. Así, puede registrąre la venta de gas boliviano al Brasil y a la Argentina ${ }^{51}$. Por su parte, Argentina, que durante los últimos años ha incrementado significativamente el descubrimiento de reservas gasíferas, se halla en negociaciones con Brasil para la venta de este recurso a ese país.

La cooperación no queda limitada a las operaciones de compra y venta de un mismo producto, sino que puede tratarse de intercambios de diferentes tipos de energía (por ejemplo, el intercambio de hidrocarburos por tecnologia nuclear). Otra modalidad es el canje de petróleo por productos de consumo o bienes de capital; en este sentido hay una propuesta que recientemente realizaron empresarios colombianos a Venezuela ${ }^{52}$ y un principio de acuerdo entre Venezuela y Trinidad-Tobago, por el cual se intercambiarian

${ }^{\circ}$ Para un comentario crítico del proyecto político, estratégico y económico d. la administración Reagan para América Central y el Caribe, ver los trabajos publicados en Cuadernos Semestrales: Estados Unidos. Perspectiva latinoamericana, del Centro de Investigación y Docencia Económica (CIDE) de México. Para una visión general del tema, ver Luis Maira, "América Latina, pieza clave de la polftica de contención de la administración Reagan", en "La administración Reagan y los lfmites de la hegemonfa norteamericana", Cuadernos Semestrales, Perspectiva Latinoamericana No 9, Ier. semestre de 1981 Mexico, D.F., CIDE).

"11"Bolivia venderá gas al Brasil”, El Universal, Caracas, 14. 2. 1982; "Negociaciones por gas boliviano en Buenos Aires", Cable IPs, 8. 2. 1982; "Giant Gas Pipelines will open new energy fronts for Brazil", Latin America Times, March, 1982.

"2:"Canje de petróleo por productos de consumo para mercado venezolano". El Universal, Caracas, 6. 2. 1983. 
Carlos J. Moneta / E1 factor energético (hidrocarburos) en las relaciones...

ciertos productos de la industria del acero por petróleo53. Las necesidades petroleras de Colombia son satisfechas por Venezuela y México, esperando ese país ser autosuficiente en 1985.

De igual manera, Brasil negocia con Venezuela y Nigeria la venta de buques mercantes (por un valor de 600 millones de dólares) a cambio de petróleo ${ }^{54}$, desarrollando un sistema de trueque. También Brasil ofreció a México pagar con petróleo los déficit del intercambio comercial bilateral y Venezuela refinaría parte de su petróleo en Brasil.

El campo de Ios servicios de asistencia en materia de tecnología petrolera ofrece enormes posibilidades. Petróleos Mexicanos (PEMEx) exporta tecnología petrolera, química y petroquímica a gran númeo de países de América Latina y el mismo tipo de tareas realiza PDVSA, de Venezuela. Ambas proveen servicios de ingeniería y capácitación técnica. Brasil posee un alto nivel tecnológico en el aprovechamiento de la biomasa y este país y Argentina cumplen papeles en el campo de la energía nuclear equivalentes a los de México y Venezuela en el petróleo, con acuerdos de asistencia técnica al Perú, México, Colombia, Venezuela y otros países de la región. Por su parte, los paises centroamericanos y del Caribe han reunido unia notable experiencia en el aprovechamiento de fuentes geotérmicas.

A nivel subregional se han firmado importantes acuerdos entre la Corporación Andina de Fomento, uno de los órganos del Acuerdo de Gartagena, y la OLADE para la cooperación conjunta de estudios de factibilidad geotérmica, el levantamiento de un inventario de los recursos energéticos de la subregión andina y la fabricación de equipos para pequeñas centrales hidroeléctricas ${ }^{55}$. Además, puede señalarse el éxito en los esfuerzos de interconexión eléctrica de la la red centroamericana, realizada con la colaboración del PNUD y con fondos de la opep.

La cooperación latinoamericana permite asimismo trascender las políticas de bloqueo al desarrollo energético o a la satisfacción de las necesidades de algunos miembros de la región realizadas por potencias extrarregionales, México, por ejemplo, firmó en 1981 un acuerdo con Cuba para colaborar con el gobierno de ese país en la prospección de hidrocarburos, en la reparación de una refinería y

\footnotetext{
Б3"Acero por petróleo se intercambiaría con Trinidad", El Unituersal, Caracas, 11. 1. 1983; "Con México y Venezuela, Colombia aseguró el suministro de petróleo", el Día, México, D.F., 17. 9. 81; "Colombia anunció autoabastecimiento petrolero para 1985", El Universal, Caracas, 29. 9. 81.

E" Brasil y Venezuela negocian intercambio comercial", El Universal, Caracas, 14. I. 1983; "Entrevista con Presidente de PEMEX", Cable ANSA, Rio de Janeiro, 28. 9. 1982; "Construirán refinería en Brasil para crudos pesados venezoIanos", El Universal, Caracas, 14. 8. 1982.

๘" OLADE y Corporación Andina desarrollarán regiones", El Universal, Caracas. 7. 2. 1982.
} 
en la provisión de asistencia técnica ${ }^{50}$. Por su parte, Venezuela concertó un acuerdo con Argentina para el suministro de derivados y petróleo crudo en ocasión del conflicto del Atlántico Sur ${ }^{57}$. Por último, los hidrocarburos pueden también constituir un motivo de acercamiento entre los regímenes políticos de distinto signo ideológico. Tal es el caso de las gestiones comerciales que se realizan entre Venezuela y Uruguay para la compra de petróleo venezolano ${ }^{58}$. La vía comercial podría facilitar la reanudación de las relaciones diplomáticas, suspendidas desde hace aproximadamente ocho años.

Obviamente, estos procesos de cooperación no están exentos de presentar situaciones de tensión. Así por ejemplo, en el marco del Acuerdo de San José, ante la dura posición que adoptara el Presidente Forbes Burnham, de Guyana, ante el mantenimiento de Ia reclamación venezolana' sobre la Guyana Esequiba, Venezuela y México decidieron no acceder a la petición de ese país de participar como beneficiario en el Acuerdo59. Sólo para mencionar otro caso, Argentina no quiso durante muchos años incorporarse a la OLADE, porque esta organización proponía un régimen de aprovechamiento de los recursos hídricos que resultaban lesivos a la posición que ese país mantenía en su diferendo con Brasil en el seno de la Cuenca del Plata; mientras, Brasil defendió un régimen jurídico para el uso de los recursos naturales en el Pacto Amazónico, que fue fuertemente resistido por Venezuela y otros países miembros de ese acuerdo, por resultar contrarios a sus intereses.

La existencia de estos desacuerdos no invalida los positivos logros obtenidos en el campo de la cooperación energética regional. Ello no significa que se haya avanzado en un grado adecuado, si bien se lograron notorios progresos con respecto a las restantes regiones en desarrollo. El proceso de cooperación exige un alto grado de voluntad política y ésta, en muchas oportunidades, es débil o se halla ausente, en virtud de múltiples causas. Entre ellas, deben ser señaladas las estrechas vinculaciones políticas y económicas con los países industrializados y las empresas transnacionales; los intereses de los actores subnacionales y de los grupos en el poder y el mantenimiento de percepciones esteoritapadas - basadas en muchos casos, en pautas históricas de conflicto- sobre los intereses, la conducta y las capacidades de otros Estados de la región. No le corresponde menor importancia a las limitaciones que imponen las continuas crisis económicas, que atentan invariablemente contra el pla-

so" México abastecerá a Cuba con material petrolero", El Diario de Caracas, Caracas, 8. 2. 1981.

"r"Acuerdo para suministrar petrólco a la Argentina anunció Calderón Berti, El Universal, Caracas, 17. 5. 1982.

${ }_{6 \sigma^{\prime}}$ El petróleo, mediador entre Uruguay y Venezuela", El Universal, Caracas, 13. 1. 1983.

sor"Burnham dice que "Guyana está preparada para defenderse", El Diario de Caracas, Caracas, 10. 4. 1981. 
Carlos J. Moneta / E1 factor energético (hidurocarburos) en las relaciones...

neamienlo de largo plazo y el mantenimiento de una acción continuada en el desarrollo de los recursos energéticos.

\section{LA ENERgfa y EL FUturo de AmÉriga LATINA}

En la actualidad, la importancia de los problemas energéticos latinoamericanos en el contexto de la crisis mundial y la existencia de organizaciones regionales que poseen parte de los mecanismos necesarios para la concertación de entendimientos políticos y la formulación de propuestas de acción, ofrece la oportunidad de armonizar las políticas energéticas de los países latinoamericanos en condiciones que aseguren una participación equitativa en los costos y benefícios de la acción común.

Los elementos centrales de este entendimiento consisten en la concreción, con carácter urgente, de las propuestas que sobre los distintos aspectos financieros, económicos y tecnológicos relacionados con la energía, han realizado la OLADE y otras organizaciones regionales (ej.: SELA) e internacionales (ej.: GEPAL), en forma armonica con la acelerada puesta en marcha del xLAGE. Ello significá la materialización de grados mucho más profundos de comunicación, intercambio de información, adopción de decisiones colectivas y una significativa reducción de los patrones de conducta de carácter decimonónimo que aún constituyen el marco de valores de referencia para tratar estos y otros aspectos del desarrollo latinoamericano. Estos requerimientos tornan sumamente difícil la tarea, reduciendo las posibilidades de éxito.

Los requisitos, en suma, no son distintos que los que rigen con carácter general para todo el proceso de integración y de cooperación regional. Los muy limitados resultados obtenidos a este nivel parecen no ofrecer buenos augurios a los avances sectoriales. Sin embargo, la energía, en razón de sus vitales interacciones con la totalidad del proceso económico y social posee, por una parte, la capacidad de transferir los logros que se obtuvieran en la cooperación energética a otros sectores y subprocesos. En otro plano, su reducción a una dimensión aparentemente sectorial ofrece la oportunidad -y también los obstáculos- de atraer a quienes favorecen los avances ad-hoc en materia de cooperación, en la búsqueda de operaciones que resultan manejables en términos de beneficio económico y limitadas temporal y espacialmente en el plano de los acuerdos políticos.

Las características de la inserción de los países latinoamericanos en el sistema económico internacional y la profunda adhesión, en varias de estas naciones, de sectores de la burocracia y de los grupos económicos dominantes a la ideología económica neoconservadora, ha contribuido a generar profundas modificaciones -en su mayor parte, altamente perjudiciales- de la estructura socioeconómica política e ideológico-cultural interna. Estos cambios, al fortalecer pa- 
trones de consumo y estilos de vida que no se corresponden con las necesidades del conjunto de las sociedades nacionales ni con la dotación de recursos de la región, han afectado negativamente las posibilidades de emprender y materializar modificaciones más profundas en las concepciones y propósitos de la política energética.

Este factor, junto a una concepción aún vigente de la "seguridad y el interés nacional", incapaz de percibir con claridad que el Estado-nación en las regiones en desarrollo sólo podrá cumplir sus metas esenciales y disminuir su vulnerabilidad externa mediante la articulación solidaria y coordinada de los esfuerzos de todos los miembros de la región, se presentan como obstáculos fundamentalès - pero en último término, manejables, por ser propios- para superar la presente etapa de crisis.

En la medida en que las presiones externas aumenten y disminuyan las vías para efectuar el tradicional "escape hacia adelante", los gobiernos latinoamericanos se verán cada vez más urgidos a optar. Existen entonces posibilidades de que la crisis los oriente hacia líneas de acción que avancen con mayor profundidad y compromiso efectivo en el camino de la cooperación e integración regional. En esta alternativa, la energía constituye uno de los elementos $y$, no puede ser aislada de los restantes factores a tener en cuenta en la concepción estratégica, dada la interdependencia de los mismos. En este contexto, la polftica externa e internacional presenta para América Latina muchas oportunidades de avanzar hacia el cumplimiento de sus objetivos.

\section{REFERENGIAS}

-Tamir Agmon y Seev Hirsch, "Multinational corporations and the developing economics: potential gains in a world of imperfect markets and uncertainty", Oxford Bulletin of economics and Statistics, noviembre de 1979.

-R. Aliber, "A theory of foreign diret investment", en G. P. Kindleberger (ed.) The international corporation, Cambridge, Mass., M.I.T. Press, 1970.

-H. Baumann, "The determinants of the pattern of foreign direct investment: some hypotheses reconsidered", Wetwirtschaftliches Archiv, 110 , 1974.

- H. F. Bergsten, T. Horst y T. Mo- ran, American Multinationals and American interests, Brookings Institution, 1977.

-W. G. Brown, "Islands of consensus power: MNCs in the theory of the firm", Bussines Topics, Summer 1976.

-P. J. Buckley y M. C. Casson, The fulure of multinational enterprise, Londres, Macmillan, 1976.

-J. Campos, G. Ondarts y E. White, Las empresas conjuntas latinoamericanas, INTAL, 1977.

$-R$. Caves, "International corporations: the industrial economics of foreign investment", Económica, 38, febrero de 1971.

-CEPAL, El desarrollo de América 
Carlos J. Moneta / $\mathrm{El}$ factor energético (hidrocarburos) en las relaciones...

Latina en los años ochenta, Estudios e Informes No 5, septiembre de 1981.

-Departamento de Comercio de los Estados Unidos, us direct investment abroad 1977, 1981 .

- Michael Duerr y John Roach, Organization and control of intemational operations, The Conference Board, 1973.

$-J$. H. Dunning, "Trade, location of economic activity and the multinational enterprise", en B. Ohlin, P. O. Hesselborn y P. J. Wiskman (eds.), The international allocation of economic aclivity, Londres. Macmillan 1977.

-J. H. Dunning, "Explaining changing patterns of international production: in defence of the eclectic theory, Oxford Bulletin of Economics and Statistics, noviembre de 1979.

-J. H. Dunning, "A note on intra-industry foreign investment", Economia Internazionale, diciembre de $198 \mathrm{I}$.

-Eduardo Fioravanti, El capital monopolista internacional, Ediciones Penf́nsula, Barcelona, 1976.

-Ricardo Ffrench-Davis, Economia internacional. Teoria y politicas para el desarrollo. Fondo de Gultura Económica, 1979.

-Edward Graham, "Transatlantic investment by multinational firms: a rivalistic phenomenon?", Journal of Post Keynesian Economics, 1978 , Vol. I, No 1.

-Gerald Helleiner, "Transnational corporations and trade structure: the role of intra-firm trade", en Herbert Giersch (editor) on the economics of intra-industry trade, JCB MLohr,Tübingen, 1979.

-Seev Hirsch, "An international trade and investment theory of the firm", Oxford Economic Papers, julio de 1976.

-T. Horst, "Firm and industry determinants of the decision to invest abroad: an empirical study", Review of Economics and Statistics, agosto de 1972.

-S. Hymer, "The multinational corporation and the law of uneven development", en J. Bhagwati (ed.)
Economics and World order, New York, World Law Fund, 1970

$-S$. Hymer, "The internationalizalization of capital", Journal of Economic Issues, Vol. 6, No 1, 1972.

$-\mathrm{H}$. Johnson, "The efficiency and welfare implications of the international corporation", en C. P. Kindleberger (ed.), The international corporation, Cambridge, Mass. M.x. T. Press, 1970.

-C. P. Kindleberger, American business abroad: six lectures on direct investment, Yale University Press, New Haven, 1969.

-P. T. Knickerbocker, Oligopolistic reaction and the multinational enterprise, Cambridge, Mass. Harvard University Press, 1973.

- Eugenio Lahera, "La división internacional del trabajo de las empresas transnacionales y los Convenios de Complementación de ALALC", Problemas del Desarrollo, agostooctubre de 1979.

-Eugenio Lahera y Hugo Nochteff, "La microelectrónica y el desarrollo latinoamericano", Revista de la GEPAL No 19, abril de 1983.

$-S$. Lall y P. Streeten, Foreign investment, transnationals and developing countries, Londres, Macmillan, 1977.

-Sanjaya Lall, "Transnationals, domestic enterprises, and industrial struture in host LDCs: a survey", Oxford Economic Papers, Vol. 30 No 2, julio de 1978.

-Sanjaya Lall, "The pattern of intra-firm exports by us multinationals", Oxford Bulletin of Economics and Statistics, Vol. 40 No 3, agosto de 1978.

$-S$. P. Magee, "Information and the multinational corporation: and appropiability theory of direct foreign investment", en J. N. Bhagwati (ed.), The new international economic order, Cambridge, Mass. M. I.T. Press, 1977.

-J. F. MciManus, "The theory of the multinational firm", en G. Piquet (ed.), The multinational firm and the national state, Toronto, Collier-Macmillan, 1972.

-P. B. Musgrave, Direct investment abroad and the multinational: ef 
fects on the U.S. economy. Informe preparado para el Comité de Relaciones Exteriores del Senado de los Estados Unidos, 1975.

-Joseph Pelzman, "Soviet-COMEcoN trade: the cuestion of intra-industry specialization", Weltuirtschaftliches Archiv, Band 114, heft 2, 1978.

-Alan Rugman, "A new theory of the multinational enterprise: internationalization versus internalization", Columbia Journal of World Business, primavera de 1980.

-D. Shapiro, "Domestic determinants of us direct foreign investment florws". Economia Internazionale, Vol. xxxir, No 1 , febrero de 1980. -J. Stopford, "Changing perspectives on investment of British manufacturing multinationals", Journal of International Business Studies, otoño-invierno 1976.

- María Conceiçao Tavares y Aloisio Teixeira, "La internacionalización del capital y las transnacionales en la industria brasileña", Revista de la CEPAL No 14, agosto de 1981.

- R. Trajtenberg y R. Vigorito, Economia y politica en la fase trans. nacional: algunas interrogantes, ILET, 198I.

-United Nations, Ecosoc, Multinational Gorporations in world development, 1973.

-United Nations, Ecosoc, Multinational corporations in world development: a re-examination, 1978.

$-R$. Vernon, "International investunent and international trade in the product cycle", Quarterly Journal of Economics, 80, 1966.

$-R$. Vernon, "The location of economic activity", en J. M. Dunning (ed.), Economic analysis and the multinational enterprise, Londres, Allen y Unwin, 1974.

$-\mathrm{R}$. Vernon, "The product cycle hypothesis in a new international environment", Oxford Bulletin of Economics and Statistics, noviembre de 1979.

-L. T. Wells, Third World Multinationals. Final Report to National Science Foundation, por aparecer en MIT Press.

$-\mathrm{B}$. Wolf, "Industrial diversification and internationalization: some empirical evidence", Journal of industrial economics, diciembre de 1977. 